\section{Leaf Unfolding Rate in Begonia $x$ hiemulis}

\section{Meriam G. Karlsson}

\section{School of Agriculture and Land Resources Management, University of Alaska Fairbanks, Fairbanks, AK 99775-0080}

Additional index words. hiemalis begonia, elatior begonia, Rieger begonia, temperature, vegetative growth

\begin{abstract}
The rate of leaf unfolding as a function of temperature was determined for Begonia $\times$ hiemalis Fotsch under long-day (16 hours of light) conditions before flower initiation. Irradiance was maintained at $280 \pm 20 \mu \mathrm{mol} \cdot \mathrm{m}^{-2} \cdot \mathrm{s}^{-1}\left(16.1 \mathrm{~mol} \cdot \mathrm{m}^{-2} \cdot \mathrm{day}^{-1}\right)$. The two cultivars Hilda and Ballet had similar rates of leaf unfolding in the range from 13 to $28 \mathrm{C}$. The rate increased to a maximum of 0.116 leaves/day at $21 \mathrm{C}$ and then decreased at higher temperature. The following quadratic function (where $T$ is the temperature in ${ }^{\circ} \mathrm{C}$ ) was selected to describe initial long-day leaf unfolding rate in $B$. $\times$ hiemalis: leaves/day $=-\mathbf{0 . 2 0 8 3}+0.03145 \times T-0.0007631 \times T^{2},\left(r^{2}=0.97\right)$. The leaf unfolding response to temperature varied for plants of 'Hilda' and 'Ballet' during short days (10 hours of light) following the initial long-day period. Plants of 'Ballet' continued to unfold leaves at a similar rate as under initial long photoperiods, while the leaf unfolding rate for 'Hilda' decreased to half the rate observed under long days.
\end{abstract}

Vegetative growth in Begonia $\times$ hiemalis (hiemalis begonia, elatior begonia, Rieger begonia) is favored by long-day (LD) conditions and reproductive growth by short days (SD). LD are initially provided to attain desired plant size for SD treatment and flower initiation. An extended period of SD results in slow leaf and shoot growth, and the plants eventually will go dormant. Plant development is therefore completed under a second LD period (Mikkelsen, 1973). Ability to follow the progression of vegetative growth would facilitate scheduling and timing of the begonia crop. For many years, rate of leaf unfolding has been used successfully to time Easter lilies. The average daily temperature controls the rate of leaf appearance in Easter lilies and other plants (Friend et al., 1962; Karlsson et. al., 1988, 1991; Rawson and Hindmarsh, 1982; Tollenaar et al., 1979). Leaf unfolding rate increases with increasing temperature to a maximum and then decreases at continued increased temperature. Knowledge of the leaf count at desired plant size for flower initiation and a temperature function describing the rate of leaf unfolding in hiemalis begonia would provide opportunities to control and maintain plant growth progression on schedule. This study was initiated to determine the rate of leaf unfolding as affected by temperature in two cultivares of $B . \times$ hiemalis.

Rooted multistem cuttings of $B . \times$ hiemalis 'Hilda' and 'Ballet' were planted in

Received for publication 4 Feb. 1991. Accepted for publication 20 Sept. 1991. Agricultural and Forestly Experiment Station, Univ. of Alaska Fairbanks Paper no. 219. Donation of plant material for this study by Mikkelsens, Inc., Ashtabula, Ohio, is appreciated. The cost of publishing this paper was defrayed in part by the payment of page charges. Under postal regulations, this paper therefore must be hereby marked advertisement solely to indicate this fact. $650-\mathrm{cm}^{3}$ square pots filled with Metromix 510 (W.R. Grace \& Co., Cambridge, Mass.). The plants were placed in growth chambers (Conviron Model E15, Ashville, N.C.) maintained at $13,16,19,22,25$, or $28 \mathrm{C}$. The average daily temperature fluctuated $+1 \mathrm{C}$ and was monitored by recording air and medium temperatures. Irradiance from cool-white fluorescent lamps (GE, F72T12, CW1500) and incandescent lamps (GE, $40 \mathrm{~W}$ ) was maintained at $280+20 \mu \mathrm{mol} \cdot \mathrm{m}^{-2} \cdot \mathrm{s}^{-1}$ for $16 \mathrm{~h}^{- \text {day }^{-1}}$ (16.1 mol-m- ${ }^{2}-$ day- $\left.^{-1}\right)$. The photosynthetic photon flux was measured using a LI-COR LI-185B meter and a LI-190SB quantum sensor (LI-COR, Lincoln, Neb.). The plants were subirrigated with a fertilizer solution of $7.1 \mathrm{~N}-1.5 \mathrm{P}-2.4 \mathrm{~K}(\mathrm{~mm})$ from Peter's 15-16-17 (W.R. Grace Co., Fogelsville, $\mathrm{Pa}$.) at 4-day intervals. The pots were spaced $12 \mathrm{~cm}$ between centers in the growth chamber.

In each temperature treatment, leaf unfolding rate was determined on 25 plants each of 'Hilda' and 'Ballet'. One shoot was selected on each plant to establish the leaf unfolding rate. The most recently expanded leaf was marked by a white dot using liquid paper correction fluid, and the number of leaves unfolded above the marked leaf was recorded daily during 3 weeks. A leaf was considered unfolded at the length of $2 \mathrm{~mm}$. Time in hours between the data collection times was recorded and used in the data analyses because the time for data collection varied from day to day. Linear regression functions were developed for the rate of leaf unfolding for each plant. The first derivative of these linear functions gave the rate of leaf unfolding (leaves/hour). After transformation from an hourly to a daily basis, these calculated rates were used in the continued regression analyses.

Multiple linear regression analysis was used to determine and describe the rate of leaf unfolding in the studied temperature range.
First-, second-, third-, and fourth-order terms of temperature were used as independent variables. Selection of final regression functions was based on significance of included independent variables, $\mathrm{F}$ and $r^{2}$ values of the equations, and the adequacy of prediction. All independent variables included in the selected functions were significant at $P=0.01$. Data collected from the two cultivars were first analyzed separately, and the resulting functions were compared using the test by Williams and Kloot (Williams, 1959). This test compares two selected functions for their ability to predict the independent variable by testing the significance of the difference between the residual sums of squares from each equation.

A second experiment was conducted under experimental conditions similar to the experiment designed for determination of leaf unfolding rates. The 50 plants each of 'Hilda' and 'Ballet' were grown for 3 weeks at 19C and LD (16 h of light) followed by 2 weeks at $21 \mathrm{C}$ and $\mathrm{SD}(10 \mathrm{~h}$ of light), and 3 weeks at $18 \mathrm{C}$ and $\mathrm{LD}$. The rate of leaf unfolding was determined during all three phases of development and reported as mean leaf unfolding rate $\pm \mathrm{SD}$.

Both cultivars had similar rates of leaf unfolding during the initial LD period. A peak leaf unfolding value was observed for both cultivars in the temperature range from 13 to 28C. Based on the test by Williams and Kloot (Williams, 1959), the two functions developed separately for 'Hilda' and 'Ballet' were not significantly different. The following functional relationship describing the leaf unfolding rate during the initial LD period in hiemalis begonia was developed using the combined leaf unfolding data from both cultivars (where $\mathrm{T}$ is the temperature in ${ }^{\circ} \mathrm{C}$ ): leaves/day $=-0.2083+0.03145 \times \mathrm{T}-$ $0.0007631 \times \mathrm{T}^{2}\left(r^{2}=0.97\right)$.

The rate of leaf unfolding for hiemalis begonia based on 'Hilda' and 'Ballet' increased to a maximum at $21 \mathrm{C}$ and then decreased toward 28C (Fig. 1). Maximum rate of leaf

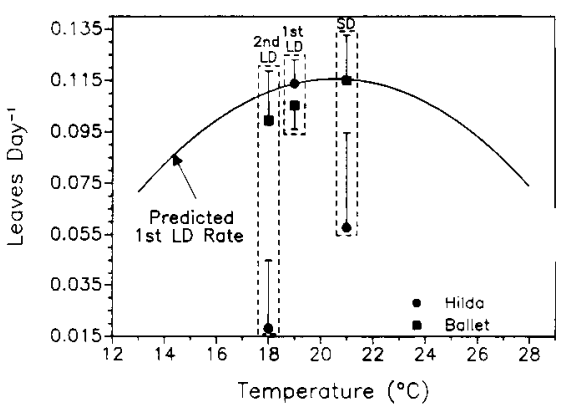

Fig. 1. Number of leaves unfolded per day as a function of temperature for Begonia $\times$ hiemalis 'Hilda' and 'Ballet'. The functional relationship for leaf unfolding rate during the initial longday period (predicted first LD rate) was: leaves/ day $=-0.2083+0.03145 \times \mathrm{T}-0.0007631$ $\times \mathrm{T}^{2}, r^{2}=0.97\left(\mathrm{~T}\right.$ is the temperature in ${ }^{\circ} \mathrm{C}$ ). The points indicate observed rates of leaf unfolding for a second group of 'Hilda' and 'Ballet' plants grown at long photoperiods (first LD), shifted to short photoperiods (SD), and allowed to complete development at long photoperiods (second LD). The vertical bars indicate SD. 
unfolding based on the selected function was 0.116 leaves/day at $21 \mathrm{C}$. Compared to many other plants, this maximum rate and the temperature promoting the highest rate of leaf appearance in hiemalis begonia were low. Maximum leaf appearance in hibiscus (Hibiscus rosa-sinensis L.) was observed at $32 \mathrm{C}$ and 0.225 leaves/day (Karlsson et al., 1991) and in maize (Zea mays L.) at 31 to $32 \mathrm{C}$ and 0.57 leaves/day (Tollenaar et al., 1979). At the maximum rate of 0.116 leaves/day for hiemalis begonia, 8.6 days are expected to be required to unfold one leaf. The estimated rate of leaf unfolding at $13 \mathrm{C}$ was 0.072 leaves/ day, and at $28 \mathrm{C}$, it was 0.074 .

Recommended temperatures for the initial phase of hiemalis begonia development is 19C (Hilding, 1982). The results presented here indicated the fastest leaf unfolding and vegetative development may be achieved at a slightly higher temperature. In the temperature range 18 to $23 \mathrm{C}$, the leaf unfolding rate showed minor variations and remained above 0.110 leaves/day as the predicted peak leaf unfolding rate was approached at $21 \mathrm{C}$. The difference in leaf unfolding rate at 19 and 21C was predicted to only 0.002 leaves/day. In most practical applications, this small difference in leaf unfolding rate is unimportant, and the recommended temperature of 19C for vegetative growth may have been chosen to optimize the overall plant development. Rate of leaf unfolding was also determined during the initial LD period on a second group of plants allowed to develop at 19C. This second group of 'Hilda' plants unfolded 0.114 \pm 0.0091 leaves/day, and plants of 'Ballet' $0.105 \pm 0.0093$ leaves/day. The predicted rate of leaf unfolding by the selected function for the initial LD period was 0.114 leaves/ day at $19 \mathrm{C}$.

Leaf unfolding in the two cultivars responded differently to SD exposure. $\mathrm{Ob}$ served rate of leaf unfolding for plants of 'Hilda' during the SD period decreased to $0.058 \pm 0.0368$ leaves/day, while 'Ballet' continued to have a similar rate $(0.115 \pm$ 0.0172 leaves/day) as during LD conditions (Fig. 1). The expected rate during the initial LD period based on the selected function at $21 \mathrm{C}$ was 0.116 leaves/day. At the observed SD rate of 0.058 leaves/day for 'Hilda', the time between the appearance of two leaves was 17 days, i.e., a longer duration of SD than the 2 weeks recommended for production would have been required to allow a more accurate measurement of leaf unfolding in plants of 'Hilda'.

The accepted recommendation for production of hiemalis begonia is to allow the plants to complete development under LD conditions (Mikkelsen, 1973) at 18C (Hilding, 1982, 1990) after SD exposure for flower initiation. During the second LD period, plants of 'Ballet' continued to have a relatively high leaf unfolding rate at $0.099 \pm 0.0193$ leaves/ day. The rate of leaf appearance in plants of 'Hilda' slowed to $0.018 \pm 0.0269$ leaves/ day during the second LD period. As a comparison, estimated rate by the selected function at $18 \mathrm{C}$ during the initial LD period was 0.114 leaves/day.

According to Powell and Bunt (1978), the rate of leaf unfolding in hiemalis begonia 'Schwabenland Red' was faster under LD than SD conditions. In a greenhouse study at a constant $18 \mathrm{C}$, a new leaf unfolded every 2 weeks ( $\approx 0.0714$ leaves/day) in LD, while the rate decreased to one leaf per month $(\approx 0.0357$ leaves/day) in SD. With the function selected in this study, holding at $18 \mathrm{C}$ would be expected to result in 0.111 leaves/ day as the initial LD rate of leaf unfolding. The rate reported here is considerably higher than the rate observed for 'Schwabenland Red' by Powell and Bunt (1978). Their primary objective was to study the expansion and growth of individual leaves. in hiemalis begonia as affected by photoperiod. Rate of leaf unfolding was of secondary interestnot precisely reported and, perhaps, measured. Although their reported absolute values were lower, the relative decrease in rate under LD and SD conditions was similar to the decrease observed here for 'Hilda'. The reported rate under SD by Powell and Bunt was half the rate observed in LD conditions. Observed rate for the second group of 'Hilda' plants at 21C and SD was 0.058 leaves/day, and the estimated initial LD rate for 'Hilda' based on the selected function at $21 \mathrm{C}$ was twice (0.116 leaves/day) the SD rate.

The photoperiodic requirements for flower initiation apparently vary among cultivars of hiemalis begonia, and some cultivars may even be day-neutral (Heide and Rtinger, 1985; Hilding, 1990). According to some reports, however, B. $\times$ hiemalis is an obligatory SD plant above $24 \mathrm{C}$ and a facultative SD plant at lower temperatures (Heide and Rünger, 1985; Hilding, 1990). The decreased rate of leaf unfolding for 'Hilda' under SD conditions suggests that photoperiod controlled the transition from vegetative to reproductive growth. Initiated by $\mathrm{SD}$, reproductive growth in 'Hilda' occurred at the expense of vegetative growth. Flowers were initiated (data not shown) in plants of 'Ballet' without any drop in leaf unfolding rate. Reproductive and vegetative growth occurred simultaneously at the studied temperatures, and 'Ballet' may be a cultivar initiating flowers independent of daylength. Efforts to control and schedule flowering in 'Ballet' by photoperiod in commercial production may be ineffective. At higher than studied temperatures, SD possibly facilitate flower initiation in 'Ballet' plants.

Rate of leaf unfolding can be used to monitor the vegetative plant development in hiemalis begonia. Timing for SD treatment is determined based on plant size and the number of developed leaves per shoot. Understanding the relationship between temperature and hiemalis begonia leaf unfolding enables scheduling and timing of SD to produce desired plant size for marketing. For cultivars initiating flowers independent of daylength, rate of leaf unfolding can be used to follow the progression of development to marketable plants with a desired number of leaves.

\section{Literature Cited}

Friend, D.J.C., V.A. Helson, and J.E. Fisher. 1962. Leaf growth in marquis wheat as regulated by temperature, light intensity, and daylength. Can. J. Bot. 40:1299-1311.

Heide, O.M. and W. Rünger. 1985. Begonia, p. 4-23. In: A.H. Halevy (ed.). Handbook of flowering. vol. II. CRC Press, Boca Raton, Fla.

Hilding, A. 1982. Production av Begonia xelatior. Trädgård 220. Swedish Univ. of Agricultural Sciences Research Information Centre, Alnarp.

Hilding, A. 1990. Begonia $\times$ elatior-odlingsbeskrivning. Trädgård 335. Swedish Univ. of Agricultural Sciences Research Information Centre, Alnarp.

Karlsson, M.G., R.D. Heins, and J.E. Erwin. 1988. Quantifying temperature-controlled leaf unfolding rates in 'Nellie White' Easter lily. J. Amer. Soc. Hort. Sci. 113:70-74.

Karlsson, M.G., R.D. Heins, J.O. Gerberick, and M.E. Hackmann. 1991. Temperature driven leaf unfolding rate in Hibiscus rosa-sinensis. Scientia Hort. 45:323-331.

Mikkelsen, J.C. 1973. Production requirements for quality rieger begonia. GrowerTalks 37(6):3-9

Powell, M.C. and A.C. Bunt. 1978. Leaf pro duction and growth in Begonia $\times$ hiemalis un der long and short days. Scientia Hort. 8:289 296.

Rawson, H.M. and J.H. Hindmarsh. 1982. Ef fects of temperature on leaf expansion in sunflower. Austral. J. Plant Physiol. 9:209-219.

Tollenaar, M., T.B. Daynard, and R.B. Hunter. 1979. Effect of temperature on rate of leaf appearance and flowering date in maize. Crop Sci. 19:363-366.

Williams, E.J. 1959. Regression analysis. Wiley, New York. p. 81-83. 